\title{
Blood Glucose Concentration Abnormalities in Children with Severe Malaria: Risk Factors and Outcome
}

\author{
Oko Aymar Pierre Gildas ${ }^{1,2 *}$, Ekouya Bowassa Gaston ${ }^{1,2}$, Lombet Laetitia1, \\ Missambou Mandilou Steve Vassili1, Kambourou Judicaël1,2, Poathy Jeysse Pierre Yoleine1, \\ Pandzou Guembo Nelly¹, Ndjobo Mamadou Ildevert Cyriaque ${ }^{1}$, Moyen Engombo1,2, \\ Moyen Georges Marius ${ }^{1,2}$
}

\begin{abstract}
${ }^{1}$ Department of Pediatrics, Teaching Hospital Center (THC) of Brazzaville, Brazzaville, Congo
${ }^{2}$ Faculty of Health Sciences, Marien Ngouabi University of Brazzaville, Brazzaville, Congo

Email: ^aymaroko@yahoo.fr, ekouyabg@yahoo.fr, letlombet@gmail.com, mstevevassili@yahoo.fr, judycokam@yahoo.fr, poaty01@yahoo.fr, pandzounelly@gmail.com, ildevert.c@gmail.com, mamy_moyen@yahoo.fr, moyengeorges@yahoo.fr
\end{abstract}

How to cite this paper: Gildas, O.A.P., Gaston, E.B., Laetitia, L., Vassili, M.M.S., Judicaël, K., Yoleine, P.J.P., Nelly, P.G., Cyriaque, N.M.I., Engombo, M. and Marius, M.G. (2017) Blood Glucose Concentration Abnormalities in Children with Severe Malaria: Risk Factors and Outcome. Open Journal of Pediatrics, 7, 222-235.

https://doi.org/10.4236/ojped.2017.74026

Received: September 9, 2017

Accepted: October 28, 2017

Published: October 31, 2017

Copyright (c) 2017 by authors and Scientific Research Publishing Inc. This work is licensed under the Creative Commons Attribution International License (CC BY 4.0).

http://creativecommons.org/licenses/by/4.0/

\begin{abstract}
Background: The place of blood glucose abnormalities in severe malaria is poorly defined. The objective of the study was to determine the incidence of glycemic abnormalities and to identify the factors associated with their occurrence and death. Patients and Methods: A prospective study was conducted from January to October 2016 at the Teaching Hospital of Brazzaville. The blood glucose levels of all children hospitalized for severe malaria were measured for 3 days. The variables were compared in univariate and multivariate analysis. Results: A total of 158 children with an average age of 69.6 months \pm 43.2 (ranges: 5 months and 15 years) were hospitalized for severe malaria. Moderate hyperglycemia was observed in $52.53 \%$ of children, severe hyperglycemia: $17.72 \%$, moderate hypoglycemia: $15.19 \%$ and severe hypoglycemia: $2.53 \%$. Children aged $<5$ years $(\mathrm{p}=0.03)$, females $(\mathrm{p}=0.03)$, with disease duration before admission $\geq 7$ days $(\mathrm{p}=0.03)$ and referred from private hospitals $(\mathrm{p}=$ 0.04 ) had an increased risk of hypoglycemia. Age $>5$ years was associated with hyperglycemia $(\mathrm{p}=0.0006)$. The presence of hypoglycemia (blood glucose $\leq 3.3 \mathrm{mmol} / \mathrm{L})$ on admission was associated with the risk of death $(\mathrm{OR}=$ 9.59, $\mathrm{p}=0.02)$, no death occurred in children with hyperglycemia $(\mathrm{p}=0.4)$ on admission. Conclusion: The incidence of blood glucose abnormalities is high in severe malaria. Hyperglycemia is more common than hypoglycemia, but only hypoglycemia is associated with an increased risk of death.
\end{abstract}

\section{Keywords}

Glucose Abnormalities, Deaths, Risk Factors, Malaria, Children 


\section{Introduction}

The World Health Organization (WHO) estimates that around 212 million of persons develop malaria every year and 429,000 die of the infection worldwide. Remarkable progress has been made in malaria control at the global level, but unfortunately this progress is slow in Sub-Saharan Africa and malaria is still responsible for high morbidity and mortality in children [1].

This morbidity and mortality are mainly related to complications, among which is hypoglycemia; the determining role of hypoglycemia in the outcome of malaria has made it one of the severity criteria as defined by WHO [2]. Its frequency varies between $3 \%$ and $20 \%$ from one country to another [3] [4] [5] [6] [7]. In Congo, the frequency of hypoglycemia during severe malaria was estimated at $5 \%$ [8]. However, these data often obtained only on admission do not necessarily reflect the true incidence of hypoglycemia in children. On the other hand, few studies have been devoted to other glycemic disorders during severe malaria. Thus hyperglycemia yet recognized as factor of poor outcome in critically ill children [9] [10] [11], has been less investigated during malaria, the same notice is made for moderate hypoglycemia [12] [13]. In a study on severe malaria in Mali, Wilcox found an increased risk of death in both groups severe and moderate hypoglycemia, while hyperglycemia had a protective role over death [12]. Thus to determine the place of glucose abnormalities in children with severe malaria in Brazzaville, we conducted this study to determine the incidence of different blood glucose abnormalities on and after admission during severe malaria, to identify factors associated with their occurrence and those associated with death.

\section{Patients and Methods}

\subsection{Study Design and Site}

It was a prospective and analytical study carried out from January to October 2016 (7 months) in the Pediatric Intensive Care Unit (PICU) of the Teaching Hospital Center (THC) of Brazzaville. Brazzaville is the capital city of the Republic of Congo, its population is estimated to $1,373,382$, and where malaria rages in the holo and hyper endemic mode. The THC of Brazzaville is the largest hospital in the country and its Pediatric ICU the only existing PICU department of the city of Brazzaville, which provide cares to seriously ill children. Thus, almost all children with severe malaria in the city are hospitalized there. The capacity of the department is 26 beds.

\subsection{Patients and Recruitment Procedure}

All children hospitalized in the PICU during the study period and meeting the criteria of severe malaria as defined by WHO in 2015 [2] were included.

Hospitalized children for severe malaria with a pre-existing known glucose metabolism disorders and those in whom blood glucose levels were not measured on admission were not included. 
Children were included in the study systematically and consecutively at the time of their admission in the department.

A standardized questionnaire, which includes sociodemographic, clinical, therapeutic and outcome data, was filled-in for all children.

The sample size was determined using the following formula suggested by Fink et al [14]:

$n=\left(\mu_{\alpha}\right) 2 \pi(1-\pi) / i^{2} ;$ where, $n=$ sample size; $\mu_{\alpha}=1.96 ; \pi=$ estimated frequency of severe malaria in Brazzaville $=10 \%$, i.e. $0.1[8] ; i=$ accuracy $=0.05$. Using the mentioned formula, a sample size of 141 children was required.

\subsection{Clinical Evaluation}

Children were examined on admission and regularly until they were discharged by one of the pediatricians of the department. Consciousness was evaluated using the Blantyre coma score [15] and the nutritional status according to WHO growth standards [16].

\subsection{Laboratory Measurements}

Immediately after arrival of patients suspected as having malaria, a blood was collected for thick test for malaria (or Malaria Rapid Diagnostic Test) and for complete blood cell count. A lumbar puncture with cerebrospinal fluid study was performed when the child had neurological manifestations. Other laboratory investigations were performed on the basis of symptoms involved. Measurements of lactate and bicarbonate were not performed due to technical difficulties.

Blood glucose concentration was measured via afingerprick measurement (using an AccuChek ${ }^{\circledR}$ Performa glucometers from ROCHE Laboratories), with sensitivity limit of $1 \mathrm{mmol} / \mathrm{L}$ on admission and every 8 hours for 3 days, and each time a seizure occurred or after a secondary worsening of the consciousness impairment was observed.

A measurement of venous blood glucose was performed to confirm hypoglycemia cases diagnosed with the glucometer.

\subsection{Treatment}

The management of patients was done according to the WHO guidelines [2] and the local consensus guidelines as well; after conditioning, children received an infusion of quinine diluted in 5\% dextrose 3 to 4 hourly or intravenous artesunate, or intramuscular artemether, associated with intravenous maintenance fluids (alternatively a $5 \%$ dextrose or $0.9 \%$ normal saline solution) at a rate of $3 \mathrm{~mL} / \mathrm{kg} / \mathrm{h}$. Parenteral treatment was administered until the child could eat and take oral drugs.

In case of hypoglycemia (blood glucose $\leq 3.3 \mathrm{mmol} / \mathrm{L}$ ) [17] [18] [19], a 5 $\mathrm{ml} / \mathrm{kg}$ intravenous bolus of $10 \%$ dextrose was administered, followed by $5 \mathrm{~mL} / \mathrm{kg} / \mathrm{h}$ of the same fluid. Blood glucose level was rechecked 30 minutes later, the same 
amount of fluid was again administered when the blood glucose level remained low; otherwise the appropriate solute to blood glucose was infused. A blood transfusion was performed when hemoglobin concentrations was below $5 \mathrm{~g} / \mathrm{dL}$ or below $7 \mathrm{~g} / \mathrm{dL}$ when clinical signs of decompensation were present.

Convulsions were managed with rectal diazepam, followed successively by intravenous midazolam, infusion of Phenobarbital when seizure could not be controlled.

\subsection{Definitions}

\subsubsection{Blood Glucose Abnormalities}

There is no consensus on the definition of different blood glucose abnormalities. The definitions used in this work were as follows [17] [18] [19] [20]:

Mild to moderate hypoglycemia: $2.2 \mathrm{mmol} / \mathrm{L} \leq$ blood glucose $\leq 3.3 \mathrm{mmol} / \mathrm{L}$; Severe hypoglycemia: blood glucose $<2.2 \mathrm{mmol} / \mathrm{L}$;

Normal blood glucose: blood glucose between 3.3 and $8.3 \mathrm{mmol} / \mathrm{L}$;

Mild to moderate hyperglycemia: $8.3 \mathrm{mmol} / \mathrm{L} \leq$ blood glucose $\leq 11.0 \mathrm{mmol} / \mathrm{L}$; Severe hyperglycemia: blood glucose $>11 \mathrm{mmol} / \mathrm{L}$.

Impaired consciousness was defined by a Blantyre coma score $(B C S)<3$; The BCS is a modification of the pediatric Glasgow coma scale, used to assess the level of consciousness in children with malaria. The score is determined by adding the results from three groups: Motor response (range from 0 - 2), verbal response (0 - 2), and eye movement $(0-1)$. The minimum score is 0 which indicates poor results while the maximum is 5 indicating good results. All scores under 5 are considered abnormal [2] [15].

Nutritional status was assessed according to the WHO growth standards [16]:

Normal nutritional status $=-2 \mathrm{z}$-score $\leq$ weight $/$ size $\leq 2 \mathrm{z}$-score;

Moderate acute malnutrition: $-3 \mathrm{z}$-score $<$ weight/height $<-2 \mathrm{z}$-score;

Severe acute malnutrition $=$ weight $/$ size $<-3 \mathrm{z}$-score;

Overweight $=2 \mathrm{z}$-score $<$ weight $/$ size $<3 \mathrm{z}$-score;

Obese $=$ weight $/$ height $>3 \mathrm{z}$-score.

\subsubsection{Statistical Analysis}

Data were processed and analyzed using Epi-Info 7.2.1 software. The quantitative variables were expressed as mean \pm standard deviation or median and interquartile range (IQR). The qualitative variables were expressed as percentages. The numbers of each variable were also specified. The comparison of percentages was carried out with the independence chi square test or the Fischer test (when at least one of the theoretical numbers was less than 5) and the odds ratio. The comparison of means was carried out using Analysis of Variance (ANOVA) or with the Mann Whitney-Wilcoxon test, the comparison of the continuous quantitative variables between them was carried out by the simple linear regression. The variables for which the p-value was $\leq 0.05$ in univariate analysis were analyzed in multivariate using the logistic regression model. The significance level was set at $5 \%$ level and the confidence interval at $95 \%$. 


\subsubsection{Ethical Considerations}

For each child an informed consent of parents or guardians was obtained. The study was carried out in compliance with the Helsinki Declaration [21]. The study was approved by the National Ethics Committee.

\section{Results}

\subsection{Description of Study Population}

During the study period, 158 children were hospitalized for severe malaria. The population was divided into 80 males (50.6\%) and 78 females (49.4\%), sex-ratio of 1.03. The mean age of the overall study population was 69.6 months \pm 43.2 (ranges 5 months and 15 years), the one for females was 60.36 months \pm 40.65 , and for males 79.61 months $\pm 44.76(\mathrm{p}=0.006)$. Children aged 5 years and above represented 82 cases $(51.9 \%)$. One hundred and twenty-five children $(79.11 \%)$ were from a health facility and $33(20.89 \%)$ from home. The median duration of symptoms before hospitalization was 4 days (IQR, 3 - 10 days).

The main criteria of severity were: multiple convulsive seizures $(n=108)$, severe anemia $(n=96)$, prostration $(n=72)$, coma $(n=52)$, hemoglobinuria $(n=$ $43)$, jaundice $(n=35)$, respiratory distress $(n=20)$, hypoglycemia $(n=4)$, shock $(\mathrm{n}=4)$, abnormal bleeding $(\mathrm{n}=2)$.

Thick for plasmodium was carried out in 108 children, and the malaria rapid diagnostic test in the other 50 children. In all cases the plasmodial species identified was Plasmodium falciparum. The median parasitic density was 10,420.00 (IQR, 640.00 - 19,968.00).

One hundred and thirteen $(71.52 \%)$ children were treated with quinine, 39 (24.68\%) with artesunate and $6(3.80 \%)$ with artemether.

The median duration of in-patient stay was 3.92 days (IQR, 3 - 5 days). One hundred and forty-six children survived, 3 with neurological sequelae ( 3 cases of hemiparesis, of which one with deafness), and 12 children (7.59\%) died, $75 \%$ of deaths occurred within 24 hours after admission.

\section{Analysis of blood glucose abnormalities:}

The mean blood glucose serum was $6.49 \mathrm{mmol} / \mathrm{L} \pm 2.42$ (ranges 1.38 and $22.17 \mathrm{mmol} / \mathrm{L}$ ), it was $6.71 \mathrm{mmol} / \mathrm{L} \pm 2.48$ (ranges, 1.38 and $14.52 \mathrm{mmol} / \mathrm{L}$ ), 6.27 $\mathrm{mmol} / \mathrm{L} \pm 2.14$ (ranges, 2.97 and $17.05 \mathrm{mmol} / \mathrm{L}$ ), $6.38 \mathrm{mmol} / \mathrm{L} \pm 2.70$ (ranges, 2.75 and $22.17 \mathrm{mmol} / \mathrm{L}$ ) and $6.77 \mathrm{mmol} / \mathrm{L} \pm 2.56$ (ranges, 2.56 and $12.93 \mathrm{mmol} / \mathrm{L}$ ) respectively on admission, on the $1^{\text {st }}, 2^{\text {nd }}$ and $3^{\text {rd }}$ days.

\subsection{Description of Blood Glucose Abnormalities}

A total of 105/158 (66.46\%) children had at least one episode of glycemic disorder on admission and during 3 days of blood glucose monitoring. Of which, 83 (52.53\%) had moderate hyperglycemia, 28 (17.72\%) severe hyperglycemia, 24 (15.19\%) moderate hypoglycemia and 4 (2.53\%) severe hypoglycemia; some children had different blood glucose abnormalities during hospitalization. Sixty (57.14\%) of the 105 children had glycemic abnormalities after admission. 
The distribution of the blood glucose categories according to the days of hospitalization is shown in Figure 1.

Twenty-three (21.90\%) of the 105 children presented the 68 observed recurrences; these recurrences consisted of 48 episodes of moderate hyperglycemia, 12 and 8 episodes of severe hyperglycemia and moderate hypoglycemia respectively. No episode of severe hypoglycemia was observed after admission.

Table 1 describes the socio-demographic, clinical and laboratory characteristics of the study population according to glycemic status on admission.

\subsection{Factors Associated with Blood Glucose Abnormalities}

As the number of children with severe hypoglycemia was low, the items severe and moderate hypoglycemias on admission were grouped as "hypoglycemia on admission" and associated factors to its occurrence were identified.

The factors associated with the risk of hypoglycemia on admission are shown in Table 2.

We did not identify any factors associated with the risk outbreak of hypoglycemia after admission, or the risk of recurrence.

Age $\geq 5$ years was the only factor significantly associated with the risk of outbreak of hyperglycemia $[\mathrm{OR}=4.83(1.85-12.60) ; \mathrm{p}=0.0006]$.

\subsection{Factors Associated with Lethality}

Factors associated with lethality were the age $<5$ years $[\mathrm{OR}=6.77(1.43-32.02)$, $\mathrm{p}=0.006$ ], hypoglycemia (moderate and severe) on admission [OR $=17,(4.53$ - 65.71), $\mathrm{p}=0.0001$ ], Blantyre score $<3$ [OR $=4.64(1.33-16.20), \mathrm{p}=0.02$ ],

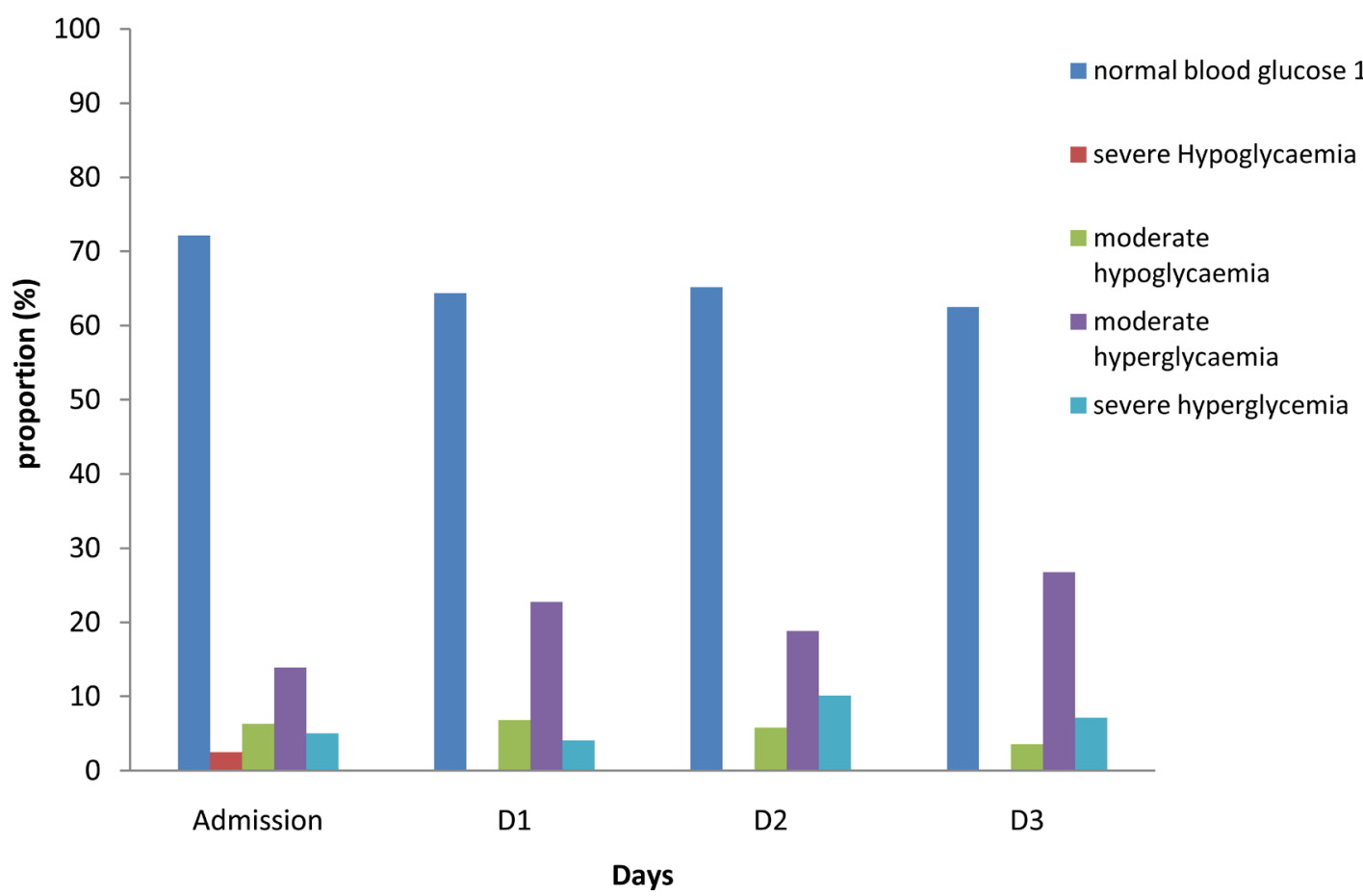

Figure 1. Distribution of the blood glucose categories according to the days of hospitalization. 
Table 1. The socio-demographic, clinical and laboratory characteristics of the study population according to glycemic status on admission.

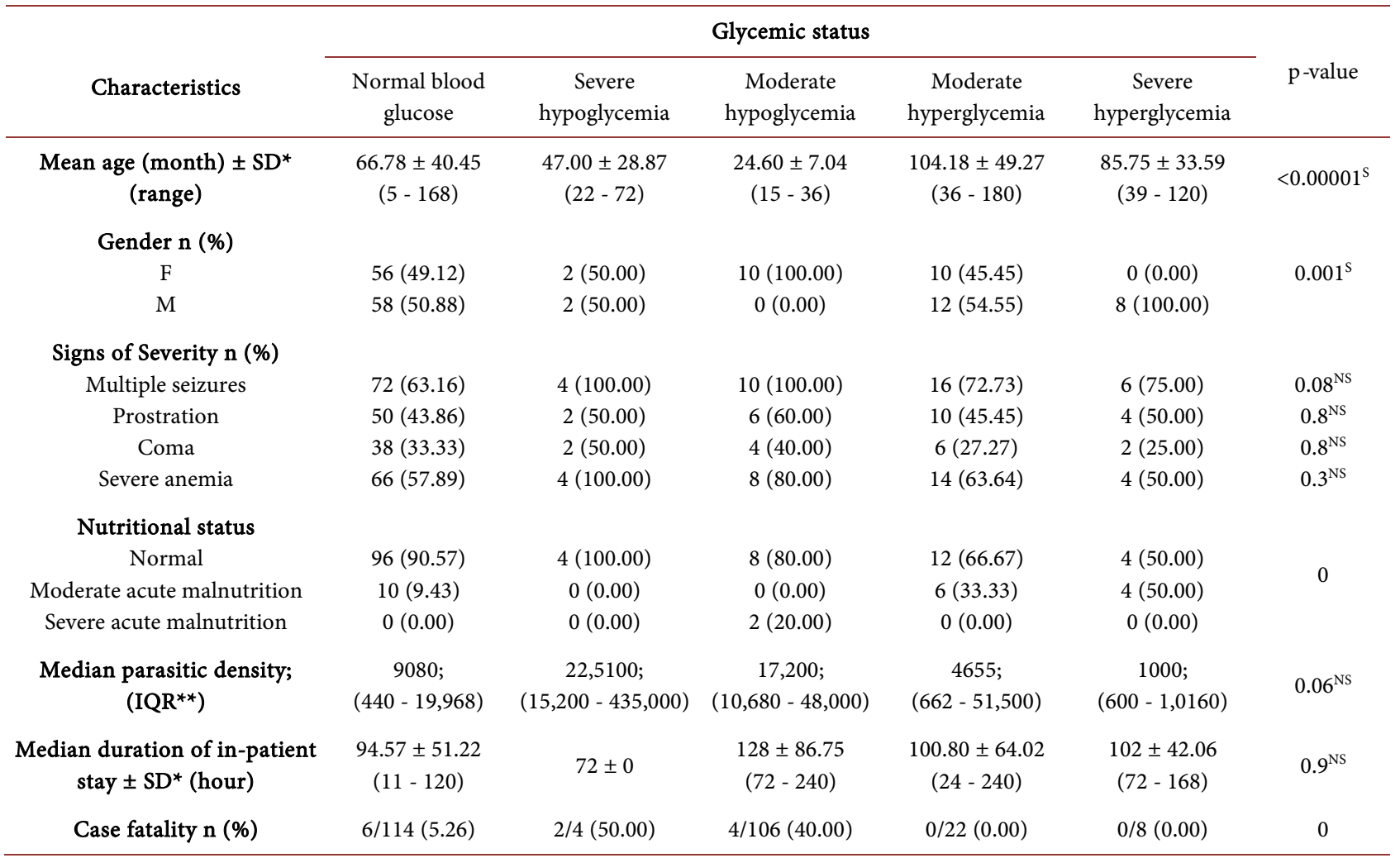

${ }^{*}$ standard deviation; ${ }^{* *}$ interquartile range, ${ }^{\mathrm{s}}$ significant difference, ${ }^{\mathrm{NS}}$ no significant difference

Table 2. Factors associated with the risk of hypoglycemia at admission.

\begin{tabular}{|c|c|c|c|c|c|c|}
\hline \multirow{2}{*}{ Variables } & \multicolumn{2}{|c|}{ Hypoglycemia n (\%) } & \multicolumn{2}{|c|}{ Univariate analysis } & \multicolumn{2}{|c|}{ Multivariate analysis } \\
\hline & no & yes & $O R\left[\mathrm{CI}^{*}\right.$ à $\left.95 \%\right]$ & $\mathrm{p}$-value & $O R$ ajusté [CI* à 95\%] & p-value \\
\hline \multicolumn{7}{|l|}{ Age (year) } \\
\hline$<5$ & $64(84.21)$ & $12(15.79)$ & $7.5(1.6-34.7)$ & 0.03 & $6.5(1.17-35.97)$ & $0.03^{\mathrm{S}}$ \\
\hline$\geq 5$ & $80(97.56)$ & $2(2.44)$ & & & & \\
\hline \multicolumn{7}{|l|}{ Gender } \\
\hline $\mathrm{F}$ & $66(84.62)$ & $12(15.38)$ & & & & \\
\hline \multicolumn{7}{|c|}{ Disease duration(day) } \\
\hline$<7$ & $118(93.65)$ & $8(6.35)$ & $3.40(1.09-10.65)$ & 0.04 & $4.5(1.10-18.32)$ & $0.03^{\mathrm{S}}$ \\
\hline$\geq 7$ & $26(81.94)$ & $6(18.75)$ & & & & \\
\hline \multicolumn{7}{|c|}{ From private hospitals } \\
\hline no & $130(92.86)$ & $10(7.14)$ & $3.71(1.02-13.41)$ & 0.03 & $5.2(1.01-26.65)$ & $0.04^{\mathrm{S}}$ \\
\hline \multicolumn{7}{|c|}{ Severe acute malnutrition } \\
\hline no & 114 & 12 & unknown & 0.007 & & $0.9^{\mathrm{NS}}$ \\
\hline yes & 0 & 2 & & & & \\
\hline \multicolumn{7}{|l|}{ Convulsion } \\
\hline yes & $94(87.04)$ & $14(12.96)$ & unknown & 0.007 & & $0.9^{\mathrm{NS}}$ \\
\hline no & $50(100)$ & $0(0)$ & & & & \\
\hline \multicolumn{7}{|l|}{ Blantyre } \\
\hline$<3$ & $46(88.46)$ & $6(11.54)$ & $1.60(0.52-4.87)$ & 0.4 & & \\
\hline$\geq 3$ & $98(92.45)$ & $8(7.55)$ & & & & \\
\hline
\end{tabular}

${ }^{*} \mathrm{CI}$ : confidence interval, ${ }^{\mathrm{S}}$ significant difference, ${ }^{\mathrm{NS}}$ no significant difference. 
respiratory distress on admission $[\mathrm{OR}=4.06(1.1-15.02), \mathrm{p}=0.04]$ and convulsion in the history $(\mathrm{p}=0.01)$ in univariate analysis, and the age $<5$ years [OR $=$ 24.09 (2.55 - 227.83), $\mathrm{p}=0.005$ ], hypoglycemia (moderate and severe) on admission $[\mathrm{OR}=9.59(1.43-63.93) ; \mathrm{p}=0.02]$, Blantyre score $<3$ [OR $=21.04$ (2.95 $149.86), \mathrm{p}=0.002]$ and respiratory distress $[\mathrm{OR}=10.75(27-91.21), \mathrm{p}=0.02]$ on admission in a multivariate analysis.

Moderate hypoglycemia after admission was not associated with lethality.

No death had been recorded among children with hyperglycemia on admission. However, there was no significant association between hyperglycemia and death $(\mathrm{p}=0.4)$.

The recurrence of any of the glycemic abnormalities did not expose the patient to excess mortality.

\section{Discussion}

This study, which is the first in Congo and one of the few in Africa devoted to glycemic disorders during severe malaria, showed that the incidence $(66.46 \%)$ of these disorders was high in children in Brazzaville. The majority of these disorders were observed after admission. Overall, hyperglycemia (70.25\%) was the most observed glycemic anomaly. These data are similar to those reported by Wilcox et al. in Mali [12], who also noted a preeminence of hyperglycemia on hypoglycemia in children hospitalized for severe malaria. But, the frequency of hyperglycemia was less important in the Wilcox study, probably because blood glucose had been measured only on admission [12]; hyperglycemia in malaria is a stress hyperglycemia, it is secondary to the increase in glucose production during severe malaria through gluconeogenesis and glycogenolysis [20] [22] [23] [24]. However, Madrid et al. in Mozambique found a higher incidence of hypoglycemia than hyperglycemia on admission and the same frequency of both abnormalities after admission [13]. This difference is related to the fact that the Madrid study population was composed of children with uncomplicated and severe malaria, and the definition of hyperglycemia (blood glucose $\geq 11.0 \mathrm{mmol} / \mathrm{L}$ ) [13] was different from the one used in our study (blood glucose $\geq 8.3 \mathrm{mmol} / \mathrm{L}$ ).

Hypoglycemia on overall was observed in $17.72 \%$ of children. This frequency is much higher than that would have been noted if blood glucose had been measured only on arrival and if the WHO definition was used [2]. Wilcox in Mali, Ogetii in Nigeria and Madrid in Mozambique found slightly lower frequencies despite the fact that they also took into account moderate hypoglycemia in their study [12] [13] [25]; differences in the definition of hypoglycemia, blood glucose monitoring modalities and population profile explain this. The frequency of moderate hypoglycemia was significantly greater than that of severe hypoglycemia in this study as in that of most authors consulted [12] [25]. Concerning severe hypoglycemia as defined by the WHO (blood glucose $<2.2 \mathrm{mmol} / \mathrm{L}$ ), its frequency was $2.53 \%$. This frequency is close to that reported by Ladhani and Nandwani respectively in the United Kingdom and India [26] [27], but lower 
than those reported by Okoko et al. in Congo in 2015, Willcox in Mali, Bassat in Mozambique, and Tripathy in India [6] [7] [8] [12]. Differences in methodology in some cases and profile of study populations in others could explain these frequency divergences.

In the present study, no case of relapse of severe hypoglycemia was observed after admission, unlike some authors who reported a relatively large number of cases [13] [28] [29]. It is difficult to make a relevant analysis of our results, because of the low number of cases of severe hypoglycemia. However, we can assume the beneficial effect of the management initiated in the ward both for correction and prevention of hypoglycemia. Indeed, Taylor et al. had also noted the beneficial effect of continuous $5 \%$ glucose intake in children with severe malaria in the prevention of hypoglycemia [29]. On the other hand, this treatment was not sufficient to prevent the occurrence of other episodes of moderate hypoglycemia; episodes that were relatively frequent in the first 48 hours. These findings confirm the need to regularly monitoring of blood glucose in any child hospitalized for severe malaria at least until the clinical condition is stabilized. Some authors have reported the efficacy of sublingual sugar administration for the correction of hypoglycemia [19] [30]. This treatment, by its simplicity, could also be tested for the prevention of hypoglycemia by systematically and regularly administering it in patients with malaria having an increased risk of developing hypoglycemia. This solution approach is not devoid of interest especially in limited resources countries where continuous glucose monitoring is not always possible.

\subsection{Factors Associated with Glycemic Abnormalities}

The factors involved in the genesis of hypoglycemia during malaria are multiple and varied depending on regions, countries and age [3] [25] [28]. It is therefore wise to identify country-specific factors in order to develop appropriate strategies for its prevention. In this work, identified factors were age $<5$ years, female gender, disease duration $>7$ days and children from private hospitals. The young age is recognized by many authors as a risk factor for hypoglycemia during severe malaria [24] [29]; young children have a limited glycogen reserves and easily develop hypoglycemia when carbohydrates requirements are increased and inadequate intakes, as observed in severe malaria [32]. Concerning the prolonged duration of the disease, malaria induces a fasting state through its symptoms (anorexia, food intolerance); the relationship between fasting, its duration and the risk of developing hypoglycemia has been demonstrated by several authors [10] [24] [31] [32] [33] [34]. Furthermore, parasitized erythrocytes have a glucose consumption 30 to 75 times higher than that of non-parasitized erythrocytes [35] [36] [37], combined with the hypercatabolism usually observed during malaria, thus it seems clear that the more the disease lasts, the higher is the risk of developing hypoglycemia. Female children were at higher risk for hypoglycemia in our study as in that of some African authors [38] [39], the young age of these children in our study (mean age of girls 60.36 months \pm 40.65 vs. 79.61 months 
\pm 44.76 for boys, $\mathrm{p}=0.006$ ) explains partly our results. But the fact that this factor here being an independent risk factor for hypoglycemia should encourage us to find another plausible explanation in an additional study. The same analysis is valid for the link between hypoglycemia and children from a private hospital.

Parasite density was higher in hypoglycemic children than in non-hypoglycemic, but without significant difference, unlike authors who reported a causal relationship between parasitic density and hypoglycemia [29] [40].

The small number of severely malnourished children did not allow to establish the link with hypoglycemia.

In this study, the only factor significantly associated with hyperglycemia was age $>5$ years. The factors (convulsions, respiratory distress, shock) usually incriminated in the genesis of hyperglycemia [12] [41], had no significant relationship with it in our study.

\subsection{The Lethality}

The case fatality rate observed in our series is as high as those reported by the majority of African authors [4] [8] [25]. Dubos et al. in France on a series of 23 children and Ladhani et al. in the United Kingdom and the Republic of Ireland on a series of 46 children had no deaths [26] [39]. The case fatality rate often varies between regions and countries; it is generally higher in African countries [4]; the inadequacy of intensive care facilities needed for the adequate management of these children is one of the reasons to that. The higher case fatality rate in African countries is sufficient evidence that malaria is still a burden for these countries, despite significant advances in the fight against malaria [1].

In this work, factors associated with risk of death were age $<5$ years, the existence of respiratory distress, impaired of consciousness (score Blantyre $<3$ ), hypoglycemia on admission. Hypoglycemia on admission was the only glycemic abnormality significantly associated with an increased risk of death [OR $=17.25$ (4.53 - 65.71)]. Our results corroborate those reported by most authors [38] [42]. The peculiarity of our results is that the blood glucose threshold exposing to an increased risk of death is significantly higher than that set by the WHO $(3.3 \mathrm{mmol} / \mathrm{L}$ vs. $2.2 \mathrm{mmol} / \mathrm{L}$ ). Like us, other African authors have also reached to the same conclusion [12] [25]. It is therefore relevant and important to review the blood glucose levels defining the severity of malaria and determining the management.

Hyperglycemia, which yet is recognized by several authors as risk factors for poor prognosis in severely ill children [9] [10] [41] [43], was not associated with the risk of death in our study. In contrast, none of children with either moderate or severe hyperglycemia on admission died. Wilcox in Mali observed a protective effect of hyperglycemia on death [12]. Further studies should be carried out to determine the actual role of hyperglycemia in the mortality of children with severe malaria.

\subsection{Limitations}

This study presents some limitations; the blood glucose assessment was per- 
formed mainly using handheld glucometer, this method not only allows a limited number of blood glucose assessments, but it's also known to underestimate hypoglycemic events, particularly in patients with anemia [44]. The use of a continuous glucose monitors would have made it possible to determine the actual incidence of glycemic abnormalities. Another limitation was the low number of cases of severe malnutrition and severe hypoglycaemia that did not allow to study their respective link with hypoglycemia and parasitic density. Finally, the information collected did not allow us to study the relationship between the type of perfused solution, disruption of glucose infusion, feed quality and blood glucose abnormalities.

\subsection{Implications}

These findings confirm the need to regularly monitoring of blood glucose in any child hospitalized for severe malaria on and after admission at least until the clinical condition is stabilized. Severe and moderate hypoglycaemia is associated with a poor prognosis child with severe malaria. Moderate hypoglycemia as well as severe hypoglycemia is associated with a poor prognosis and should be the subject of prevention and management.

\section{Conclusions}

Hypoglycemia, the only glycemic disorder associated with risk of death in children with malaria, is much more common than would suggest the only blood glucose measurement on admission. The revision of the threshold defining its severity, the implementation of simple and effective control measures against it other factors of severity are necessary to hope to reduce the lethality related to malaria.

Hyperglycemia, which is the most common glycemic disorder, appears to have a protective effect in children severely affected by malaria.

\section{Acknowledgements}

We are indebted to children and mothers who participated in the study.

We acknowledge all our colleagues, especially the nursing staff of the Pediatric Intensive Care Unit and the laboratory workers of the Teaching Hospital Center of Brazzaville.

\section{Competing Interests}

The authors declare that they have no competing interests.

\section{References}

[1] WHO (2016) World Malaria Report. World Health Organization, Geneva.

[2] WHO (2015) Guidelines for Treatment of Malaria. 3rd Edition, World Health Organization, Geneva.

[3] Madrid, L., Lanaspa, M., Maculuve, S.A. et al. (2015) Malaria-Associated Hypogly- 
cemia in Children. Expert Review of Anti-Infective Therapy, 13, 267-277. https://doi.org/10.1586/14787210.2015.995632

[4] Manning, L., Laman, M., Davi,s W.A. and Davis, T.M.E. (2014) Clinical Features and Outcome in Children with Severe Plasmodium falciparum Malaria: A Meta Analysis. PLoS ONE, 9, e86737. https://doi.org/10.1371/journal.pone.0086737

[5] Jallow, M., Casals-Pascual, C., Ackerman, H., et al. (2012) Clinical Features of Severe Malaria Associated with Death: A 13-Year Observational Study in the Gambia. PLoS ONE, 7, e45645. https://doi.org/10.1371/journal.pone.0045645

[6] Bassat, Q., Guinovart, C., Sigauque, B., et al. (2008) Malaria in Rural Mozambique. Part II: Children Admitted to Hospital. Malaria Journal, 7, 37.

https://doi.org/10.1186/1475-2875-7-37

[7] Tripathy, R., Parida, S., Das, L., et al. ( 2007) Clinical Manifestations and Predictors of Severe malaria in Indian children. Pediatrics, 120, e454-e460. https://doi.org/10.1542/peds.2006-3171

[8] Okoko, A.R. et al. (2016) Paludisme grave au Centre hospitalier universitaire de Brazzaville. [Severe Malaria of the Child at the University of Brazzaville.] Journal de Pédiatrie et de Puériculture, 29, 304-309.https://doi.org/10.1016/j.jpp.2016.09.004

[9] Sambany, E., Pussard, E., Rajaonarivo C., et al. (2013) Childhood Dysglycemia: Prevalence and Outcome in a Referral Hospital. PLoS ONE, 8, e65193 5. https://doi.org/10.1371/journal.pone.0065193

[10] Osier, F.H., Berkley, J.A., Ross, A., et al. (2003) Abnormal Blood Glucose Concentrations on Admission to a Rural Kenyan District Hospital: Prevalence and Outcome. Archives of Disease in Childhood, 88, 621-625. https://doi.org/10.1136/adc.88.7.621

[11] Mekitarian Filho, E., Carvalho, W.B. and Troster, E.J. (2009) Hiperglicemia e morbimortalidade em crianças graves análise crítica baseada em revisão sistemática. [Hyperglycemia, Morbidity and Mortality in Critically Ill Children-Critical Analysis Based on a Systematic Review.] Revista Da Associacao Medica Brasileira, 55, 475-483. https://doi.org/10.1590/S0104-42302009000400026

[12] Willcox, M.L., Forster, M., Dicko, M.I., et al. (2010) Blood Glucose and Prognosis in Children with Presumed Severe Malaria: Is There a Threshold for "Hypoglycemia"? Tropical Medicine \& International Health, 15, 232-240. https://doi.org/10.1111/j.1365-3156.2009.02444.x

[13] Madrid, L., et al. (2017) Continuous Determination of Blood Glucose in Children Admitted with Malaria in a Rural Hospital in Mozambique. Malaria Journal, 16, 184. https://doi.org/10.1186/s12936-017-1840-X

[14] Fink, R. and Kosecoff, J. (1985) How to Conduct Surveys: A Step by Step Guide? Sage Publications Inc., London, 53-63.

[15] Molyneux, M.E., Taylor, T.E., Wirima, J.J. and Borgstein, A. (1989) Clinical Features and Prognostic Indicators in Pediatric Cerebral Malaria: A Study of $131 \mathrm{Com}-$ atose Malawian Children. The Quarterly Journal of Medicine, 265, 441-459.

[16] WHO (2006b) WHO Child Growth Standards: Length/Height for Age, Weight for Age, Weight for Length, Weight for Height and Body Mass Index-for-Age: Methods and Development. World Health Organization, Geneva.

[17] Ly, T.T., Maahs, D.M., Rewers, A., Dunger, D., Oduwole, A. and Jones, T.W. (2014) ISPAD Clinical Practice Consensus Guidelines-Hypoglycemia: Assessment and Management of Hypoglycemia in Children and Adolescents with Diabetes. Pediatric Diabetes, 15, 180-192. https://doi.org/10.1111/pedi.12174 
[18] Nicholson, J. and Pesce, M. (2004) Reference Range for Laboratory Tests and Procedures. In: Behrman, R., Kleigman, R. and Jenson, H., Eds., Nelson Textbook of Pediatrics, Philadelphia Saunders, 2396-2427.

[19] Barennes, H., Valea, I., Nagot, N., Van de Perre, P. and Pussard, E. (2005) Sublingual Sugar Administration as an Alternative to Intravenous Dextrose Administration to Correct Hypoglycemia among Children in the Tropics. Pediatrics, 116, e648-e653. https://doi.org/10.1542/peds.2004-2218

[20] Valerio, G., Franzese, A., Carlin, E., Pecile, P., Perini, R. and Tenore, A. (2001) High Prevalence of Stress Hyperglycemia in Children with Febrile Seizures and Traumatic Injuries. Acta Paediatrica, 90, 618-622.

https://doi.org/10.1080/080352501750258658

[21] World Medical Association: Declaration of Helsinki. http://www.wma.net/policies-post/wma-declaration-of-helsinki-ethical-principles-f or-medical-research-involving-human-subjects/

[22] Dekker, E., et al. (1997) Glucose Homeostasis in Children with Falciparum Malaria: Precursor Supply Limits Gluconeogenesis and Glucose Production. The Journal of Clinical Endocrinology \& Metabolism, 82, 2514-2521. https://doi.org/10.1210/jc.82.8.2514

[23] Thien, V.H., et al. (2001) Glucose Production and Gluconeogenesis in Adults with Cerebral Malaria. The Quarterly Journal of Medicine, 94, 709-715. https://doi.org/10.1093/qjmed/94.12.709

[24] Zijlmans, W.C.W.R., van Kempen, A.A.M.W., Ackermans, M.T., de Metz, J., Kager, P.A. and Sauerwein, H.P. (2008) Very Young Children with Uncomplicated Falciparum Malaria Has Higher Risk of Hypoglycemia: A Study from Suriname. Tropical Medicine \& International Health, 13, 626-634. https://doi.org/10.1111/j.1365-3156.2008.02064.x

[25] Ogetii, G.N., Akech, S., Jemutai, J., Boga, M., Kivaya, E., Fegan, G., et al. (2010) Hypoglycaemia in Severe Malaria, Clinical Associations and Relationship to Quinine Dosage. BMC Infectious Diseases, 10, 334. https://doi.org/10.1186/1471-2334-10-334

[26] Ladhani, S., Garbash, M., Whitty, C.J., Chiodini, P.L., Aibara, R.J., Riordan, F.A., et al. (2010) Prospective, National Clinical and Epidemiologic Study on Imported Childhood Malaria in the United Kingdom and the Republic of Ireland. The Pediatric Infectious Disease Journal, 29, 434-438.

https://doi.org/10.1097/INF.0b013e3181c4d97c

[27] Nandwani, S., Pande, A. and Saluja, M. (2014) Clinical Profile of Severe Malaria: Study from a Tertiary Care Center in North India. Journal of Parasitic Diseases, 38, 11-15. https://doi.org/10.1007/s12639-012-0208-y

[28] English, M., Wale, S., Binns, G., Mwangi, I., Sauerwein, H. and Marsh, K. (1998) Hypoglycaemia on and after Admission in Kenyan Children with Severe Malaria. The Quarterly Journal of Medicine, 91, 191-197. https://doi.org/10.1093/qjmed/91.3.191

[29] Taylor, T.E., Molyneux, M.E., Wirima, J.J., Fletcher, K.A. and Morris, K. (1988) Blood Glucose Levels in Malawian Children before and during the Administration of Intravenous Quinine for Severe Falciparum Malaria. The New England Journal of Medicine, 319, 1040-1047. https://doi.org/10.1056/NEJM198810203191602

[30] Graz, B., Dicko, M., Willcox, M.L., Lambert, B., et al. (2008) Sublingual Sugar for Hypoglycemia in Children with Severe Malaria: A Pilot Clinical Study. Malaria Journal, 23, 242. https://doi.org/10.1186/1475-2875-7-242 
[31] Davies, T.M.E., Looareesuwan, S., Pukrittayakamee, S., Levy, J.C., Nagachinta, B. and White, N.J. (1993) Glucose Turnover in Severe Falciparum Malaria. Metabolism, 42, 334-340.

[32] Zijlmans, W., van Kempen, A., Ackermans, M., et al. (2008) Glucose Kinetics during Fasting in Young Children with Severe and Non-Severe Malaria in Suriname. The American Journal of Tropical Medicine and Hygiene, 79, 605-612.

[33] Thien, H.V., Kager, P.A. and Sauerwein, H.P. (2006) Hypoglycemia in Falciparum Malaria: Is Fasting an Unrecognized and Insufficiently Emphasized Risk Factor? Trends in Parasitology, 22, 410-415.

[34] Bennish, M.L., et al. (1990) Hypoglycemia during Diarrhea in Childhood: Prevalence, Pathophysiology, and Outcome. The New England Journal of Medicine, 322, 1357-1363. https://doi.org/10.1056/NEJM199005103221905

[35] Sherman, I.W. (1979) Biochemistry of Plasmodium. Microbiological Reviews, 43, 453-495.

[36] Phillips, R.E. (1989) Hypoglycemia Is an Important Complication of falciparum Malaria. The Quarterly Journal of Medicine, 71, 477-483.

[37] Newton, C.R.J.C. and Krishna (1998) Severe falciparum Malaria in Children: Current Understanding of Pathophysiology and Supportive Treatment. Pharmacology \& Therapeutics, 79, 1-53.

[38] Mockenhaupt, F.P., Ehrhardt, S., Burkhardt, J., Bosomtwe, S.Y., Laryen, S., et al. (2004) Manifestations and Outcome of Severe Malaria in Children in Northern Ghana. The American Journal of Tropical Medicine and Hygiene, 71, 167-172.

[39] Dubos, F., et al. (2010) Imported Malaria in Children: Incidence and Risk Factors for Severity. Diagnostic Microbiology and Infectious Disease, 66, 169-174.

[40] Agbenyega, T., Angus, B.J., Bedu-Addo, G., Baffoe-Bonnie, B., Guyton, T., et al. (2000) Glucose and Lactate Kinetics in Children with Severe Malaria. The Journal of Clinical Endocrinology \& Metabolism, 85, 1569-1576. https://doi.org/10.1210/jc.85.4.1569

[41] Preissig, C.M. and Rigby, M.R. (2009) Pediatric Critical Illness Hyperglycemia: Risk Factors Associated with Development and Severity of Hyperglycemia in Critically Ill Children. Journal of Pediatrics, 155, 734-739.

[42] Kendjo, E., Agbenyega, T., Bojang, K., Newton, C.R.J.C., Bouyou-Akotet, M., et al. (2013) Mortality Patterns and Site Heterogeneity of Severe Malaria in African Children. PLoS ONE, 8, e58686. https://doi.org/10.1371/journal.pone.0058686

[43] Srinivasan, V., Spinella, P.C., Drott, H.R., Roth, C.L., Helfaer, M.A. and Nadkarni, V. (2004) Association of Timing, Duration, and Intensity of Hyperglycemia with Intensive Care Unit Mortality in Critically Ill Children. Pediatric Critical Care Medicine, 5, 329-336. https://doi.org/10.1097/01.PCC.0000128607.68261.7C

[44] Mann, E.A., Pidcole, H.F., Salinas, J., Wade, C.E., Holcomb, J.B. and Wolf, S.E. (2007) Accuracy of Glucometers Should No Be Assumed. American Journal of Critical Care, 16, 531-532. 